\title{
Patient compliance to postoperative instructions after third molar surgery comparing traditional verbally and written form versus the effect of a postoperative phone call follow-up a: A randomized clinical study
}

\author{
Amparo Aloy-Prósper ${ }^{1}$, Hilario Pellicer-Chover ${ }^{2}$, José Balaguer-Martínez ${ }^{3}$, Oscar Llamas-Monteagudo ${ }^{4}$, \\ Miguel Peñarrocha-Diago ${ }^{5}$
}

${ }^{1}$ DDS, PhD. Assistant Professor of Oral Surgery, Stomatology Department, Faculty of Medicine and Dentistry, University of Valencia, Spain

${ }^{2}$ DDS, PhD. Collaborating Professor of the Master in Oral Surgery and Implant Dentistry, Stomatology Department, Faculty of Medicine and Dentistry, University of Valencia, Spain

${ }^{3}$ DDS, MSc. Student of Master in Oral Surgery and Implant Dentistry, Stomatology Department, Faculty of Medicine and Dentistry, University of Valencia, Spain

${ }^{4}$ Master in Oral Surgery and Implant Dentistry, Stomatology Department, Faculty of Medicine and Dentistry, University of Valencia, Spain

${ }^{5} \mathrm{MD}$, PhD. Chairman of Oral Surgery, Stomatology Department, Faculty of Medicine and Dentistry, University of Valencia, Spain

Correspondence:

Clínicas Odontológicas

Gascó Oliag 1

46021 - Valencia (Spain)

amparo.aloyprosper@gmail.com

Aloy-Prósper A, Pellicer-Chover H, Balaguer-Martínez J, Llamas-Monteagudo $\mathrm{O}$, Peñarrocha-Diago $\mathrm{M}$. Patient compliance to postoperative instructions after third molar surgery comparing traditional verbally and written form versus the effect of a postoperative phone call follow-up a: A

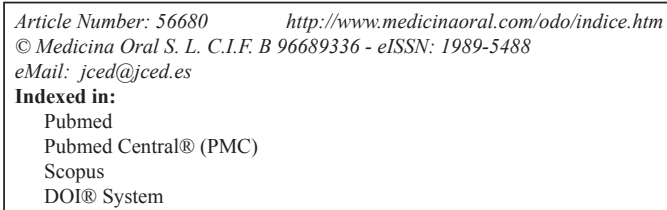

\begin{abstract}
Background: The understanding and adherence to postoperative care instructions may be influenced by how they are presented by the professional interfering the recuperation process after surgery. The aim of this study was to evaluate the effect of a postoperative phone call follow-up compared with a traditional verbally and written instructions regarding compliance of postoperative recommendations after third molar surgery; and secondly, to discover the main points of non-compliance.

Material and Methods: A randomized clinical study was performed including patients that underwent surgical extraction of an impacted mandibular or maxillary third molar in the Oral Surgery Unit of the University of Valencia from January 2016 to January 2017. Patients were randomly assigned to one of three different test groups according to how the post-operative instructions were delivered: brief written instructions, written extended instructions or brief written instructions plus a phone call follow-up at 3-day postoperative period. Patients were interviewed about their adherence to the instructions one week after surgery. The significance level was set at $p<0.05$.

Results: The higher score of compliance was found to the phone call follow-up group ( $p=0.001)$. No statistically significant differences were found between brief written group and the group that received written extended instructions. In the phone call follow-up group all variables assessed to the compliance were fulfilled. To brief written and written extended instructions groups, the main points of non-compliance were hygiene and smoking $(p<0.001$, $p=0.026$, respectively), and tended towards significance for chlorhexidine rinses and antibiotic, analgesic and anti-inflammatories medication prescribed.
\end{abstract}


Conclusions: Telephone call follow-up can promote patient adherence to postoperative recommendations after third molar surgery. The main factors of non-compliance were not maintain a proper hygiene and not smoking, followed by not performing chlorhexidine rinses and not following medication prescribed.

Key words: Compliance, postoperative instructions, postoperative recommendations, third molar surgery.

\section{Introduction}

Surgical removal of impacted third molars remains one of the most common procedures performed by oral and maxillofacial surgeons (1). The understanding and adherence to postoperative care instructions may be influenced by how they are presented by the professional (verbally and/or written) interfering the recuperation process after surgery (2).

Few reports are published regarding the surgeon's explanations and patient comprehension and implementation of the instructions after oral surgical procedures (26 ), especially in third molar surgery literature is scarce $(2,5)$. Some studies have shown that written instructions are a valuable supplement to verbal instructions in order to increase patient understanding $(4,5)$. However, a clinical trial published by Alvira-González \& Gay-Escoda (2) did not find differences in the adherence to postoperative instructions regarding how they were provided to the patient (verbal, written and a group that received written additional information). Atchison et al. (7) found that approximately $41 \%$ of patients recalled elements of postoperative instructions over postoperative period. Previous studies, although not dental reports, demonstrated that a telephone call follow-up is a safe and cost-effective method to ensure and maintain optimal patient outcomes (8-12). To the best of the authors' knowledge, this is the first work that analyzes the benefit of a phone call follow-up to improve the compliance of postoperative recommendations in the field of dentistry. The hypothesis is that a phone call follow-up during the postoperative period will enhance the implantation of the instructions and address any questions or concerns after third molar surgery.

The main objective of this study was to evaluate the effect of a postoperative phone call follow-up compared with a traditional verbally and written instructions regarding compliance of postoperative recommendations after third molar surgery; and secondly, to discover the main points of non-compliance.

\section{Material and Methods}

-Study design

A randomized clinical trial was performed including patients that underwent surgical extraction of an impacted mandibular or maxillary third molar in the Oral Surgery Unit of the University of Valencia from January 2016 to January 2017 . The study was performed following the instructions of the Declaration of Helsinki for human research. Accordingly, all patients received information about the study, and were asked to sign a written informed consent form before taking part. The study design was approved by the Ethics Committee of the University of Valencia (Ref.: H1450093433934). The present study is presented in accordance with the CONSORT statement (13).

\section{-Selection Criteria}

The inclusion criteria were healthy patients, older than 18 years who agreed to participate in the study and signed an informed consent. The exclusion criteria were patients with mental conditions or psychological disorders that do not allow them to understand and implement the postoperative instructions, and those who could not attend the scheduled appointments.

\section{-Randomization}

Patients were randomly assigned to one of the following three study groups (sequence generated by a computer program (IBM SPSS v21; IBM Corp) macro (!RNDSEQ; Domenech JM, Granero R):

- Group 1. Brief written instructions: usual postoperative instructions were given verbal and on paper briefly (Table 1).

- Group 2. Written extended instructions: instructions and postoperative medication were given both verbally and written, and extended written information about the postoperative period was also provided (Table 1).

- Group 3. Reinforcement phone call follow-up: instructions were given verbally and on paper briefly (as group 1 ), in addition patients were phoned at 3 day after surgery to ensure the compliance of recommendations.

Postoperative information provided was based on Alvira-Gonzalez \& Gay-Escoda study (2). Patients did not receive any financial compensation for their participation in the study. All surgeons involved in the study were blinded, as well as the researcher and the statistician. The recommendations and recalls were delivered by a different clinician to surgeon.

-Procedure

The surgery was performed under local anesthesia with 4\% articaine 1:100.000 adrenalin (Inibsa, Lliça of Vall). A vestibular triangular mucoperiosteal flap was raised with a distal incision and vestibular release. The osteotomy and odontectomy were made using a rounded tungsten carbide drill, mounted in a hand piece, with abundant irrigation of sterile physiologic serum. After 
Table 1: Brief and extended postoperative information provided after the third molar surgery.

\section{Brief written instructions}

1- Keep pressing folded gauze for 30 minutes after extraction. Do not spit.

2- Avoid rinsing with any liquid for the first 24 hours.

3- Take a soft or semi-liquid diet at low or warm temperature.

4- Apply ice wrapped in a cloth on the outside of the face where the extraction has been performed.

5- Maintain proper hygiene (brushing the surgical area very gently).

6- Avoid smoking during the postoperative period (7 days after surgery) and do not consume alcoholic/soft drinks during the week after.

7- Do not take carbonated drinks.

8- Take antibiotics according to the recommendations of the surgeon (pay attention to the prescription of each medication and observe the times indicated).

9- Take analgesics, anti-inflammatories according to the recommendations of the surgeon (pay attention to the prescription of each medication and observe the times indicated).

10- Perform rinses with chlorhexidine $0.12 \%$ from 24 hours (3 times each day / 10 days) starting the day after surgery.

\section{Written extended instructions}

1- It is important to keep pressing folded gauze for 30 minutes after extraction to prevent haemorrhage (bleeding). For several hours, saliva can be slightly bloody. This should be swallowed, never spit. Do not perform work or exercise that requires significant efforts. In case of heavy bleeding, remove blood using a gauze, place another gauze on the bleeding area (not cottonwood), and press it with your teeth for 30 minutes (repeat 2-3 times). If the bleeding continues, contact your surgeon.

2- It is important not to rinse during the first $24 \mathrm{~h}$ to avoid dislodging the clot of the wound. For this reason, also avoid physical effort.

3- Take a soft or semi-liquid diet at low or warm temperature. It is advisable to chew on the opposite side. Avoid hot and irritating foods.

4- Apply cold (ice pack) during the first 24 hours to help reduce inflammation and discomfort. Apply ice wrapped in a cloth on the outside of the face where the extraction has been performed in order to reduce swelling.

5- It is very important to maintain proper hygiene to prevent postoperative infection. Brush your teeth as usual, three times daily, and brush the wound using a surgery toothbrush in the affected area. It should be performed after every meal. Maintain sutures clean, brush them gently. A lower brushing frequency has been demonstrated to increase pain.

6- Avoid smoking during the postoperative period (7 days after surgery) as increase infection rates and delays time healing. Do not consume alcoholic/soft drinks during the week after surgery. Smoking after surgery has been demonstrated to increase pain.

7- Do not take carbonated drinks as blood coagulate could be weaken and move.

8- Take antibiotics according to the recommendations of the surgeon (pay attention to the prescription of each medication and observe the times indicated).

9- Take analgesics, anti-inflammatories according to the recommendations of the surgeon (pay attention to the prescription of each medication and observe the times indicated).

10- Perform rinses with chlorhexidine $0.12 \%$ from 24 hours (3 times each day / 10 days) starting the day after surgery. Chlorhexidine is an antiseptic reduces oral bacteria contributing to avoid a postoperative infection. A low level of bacterial plaque is associated with a lesser probability of side effects and postoperative complications.

*Extended information: Trismus (difficulty in opening the mouth) is a common complication after extraction of a wisdom tooth, which gradually disappears with time. It manifests as tightness in the back of the jaw. Surgical extraction of third molars causes moderate pain and swelling during the first 24 hours after surgery. Facial edema usually occurs several hours after surgery, increasing even during the first 2-3 postoperative days. Postoperative pain can last several days (4-5 days), increasing especially at night and after meals. 
extracting the molar, the cavity was inspected and sutured with 3-0 silk (Lorca Marin, TB15, 3/8, Murcia, Spain). All patients received postoperative antibiotic treatment: amoxicillin $500 \mathrm{mg}, 3$ times during 1 week. Ibuprofen $600 \mathrm{mg}, 3$ times daily during 4 days, and patients were instructed to rinse with $0.2 \%$ chlorhexidine. Sutures were removed one week after the surgery. All surgical procedures were carried out by surgeons with similar experience of the Master of Oral Surgery and Implantology of the University of Valencia. After the surgical procedure, postoperative recommendations were given according to the study groups.

-Data collected

At surgery, the following variables were recorded: age, gender, tooth to be extracted (relative position and arcade), frequency of brushing ( $\geq 3$ times/day; 1-2 times/ day) smoking habits (no smoking; $<10$ cigarettes/day; 10-20 cigarettes/day; $>20$ cigarettes/day) and surgical difficulty using Pell\&Gregory index (1933). The principal predictor variable was how the recommendations were given (brief written instructions, written extended instructions and a reinforcement postoperative phone-call).

The primary outcome variable of interest was the score of compliance of postoperative instructions. Patients were interviewed about their adherence to the instructions one week after the surgery, at the time of suture removal. They were requested about the compliment of the instructions (Table 2). For each patient, the final score was the sum of the scores for each question (maximum 10 points).

-Statistical analysis

The collected data was tabulated and statistically evaluated. Frequency distribution and percentage analysis were done. Homogeneity between patient groups was analyzed using parametric tests in the quantitative variables, as them showed a normal distribution (Shapiro-Wi$1 \mathrm{k}$ and Kolmogorov-Smirnov tests $p>0.05$ ). Chi-square test was used to evaluate homogeneity regarding sex, hygiene, smoking habits and surgical difficulty, while the t-Student was used to evaluate homogeneity regarding age. ANOVA test was used to compare the compliance and how the postoperative instructions were provided (brief written, extended written instructions and postoperative phone call follow-up). A linear regression model was used to analyze the total score obtained in compliance regarding each of the parameters studied.

To our knowledge, there were no studies in the literature about the influence of a phone call in the adherence to the instructions provided to the patient. It was necessary to determine the size of the effect and calculate the sample size. An initial sample of 40 patients allocated for each group by simple randomization was determined. It was found a size effect of 1.38 (short group mean = 8.39 , call group $=9.89$, pooled $\mathrm{SD}=1.08$ ). To ensure a power of $90 \%$ capable of detecting an effect of 1 with a confidence of $95 \%$ and alpha set at 0.05 , it was needed to include a minimum of 18 subjects of every group. An additional $20 \%$ of patients were included in the trial to prevent statistical power loss for attrition. Statistical analysis was completed using SPSS 21.0 software (SPSS Inc., Chicago, IL).

\section{Results}

Seventy-seven patients underwent third molar surgery. Eight patients were excluded because they did not attend to the 7-day follow-up visit ( 2 brief written instructions group, 2 extended written instructions group, 4 pho-

Table 2: Questionnaire to assess the compliance of postoperative instructions following the third molar surgery.

\begin{tabular}{|c|c|c|}
\hline Items & $\begin{array}{l}\text { Yes } \\
\text { (1 point) }\end{array}$ & $\begin{array}{l}\text { No } \\
(\mathbf{0} \text { point) }\end{array}$ \\
\hline 1. Did you keep pressing folded gauze for 30 minutes after extraction? & & \\
\hline 2. Did you avoid rinsing with any liquid for the first 24 hour? & & \\
\hline 3. Did you take a soft or semi-liquid diet at low or warm temperature? & & \\
\hline $\begin{array}{l}\text { 4. Did you apply ice wrapped in a cloth on the outside of the face where the extraction } \\
\text { has been performed? }\end{array}$ & & \\
\hline 5. Did you maintain proper oral hygiene? & & \\
\hline 6. Did you avoid smoking during the postoperative period (7 days after surgery)? & & \\
\hline 7. Did you take carbonated drinks? & & \\
\hline 8. Did you take antibiotics according to the recommendations of the surgeon? & & \\
\hline $\begin{array}{l}\text { 9. Did you take analgesics and anti-inflammatories according to the recommendations } \\
\text { of the surgeon? }\end{array}$ & & \\
\hline $\begin{array}{l}\text { 10. Did you perform rinses with chlorhexidine } 0.12 \% \text { from } 24 \text { hours ( } 3 \text { times each day / } \\
10 \text { days) starting the day after surgery? }\end{array}$ & & \\
\hline TOTAL SCORE (Sum of the scores above) & & \\
\hline
\end{tabular}


ne-call follow-up group). The final study sample included 69 patients (34 women and 35 men) with an average age of $25.9 \pm 9.2$ years (range 18 to 45 ). Sample size and composition is shown in table 3 , with no statistically significant differences between groups.
Overall, after applying linear regression analysis, a very high goodness of fit $(\mathrm{R} 2=0.983)$ was observed. The most important factor to the non-compliance (score variable) was hygiene, with a variation of $25.2 \%(p=0.0001)$, followed by smoking with $19.1 \%(p=0.0001)$, chlorhexi-

Table 3: Description of the patient sample per group.

\begin{tabular}{|c|c|c|c|c|}
\hline Variable & $\begin{array}{c}\begin{array}{c}\text { Brief } \\
\text { written }\end{array} \\
(n=23)\end{array}$ & $\begin{array}{c}\text { Extended } \\
\text { written } \\
(\mathbf{n}=\mathbf{2 5})\end{array}$ & $\begin{array}{c}\text { Phone call } \\
\text { follow-up } \\
(n=21)\end{array}$ & $P$ value \\
\hline Age & $\begin{array}{c}28.8 \pm \\
12.6\end{array}$ & $24 \pm 5.7$ & $24.4 \pm 7.2$ & 0.179 \\
\hline \multicolumn{4}{|l|}{ Gender } & \multirow[t]{3}{*}{0.298} \\
\hline Men & 13 & 8 & 7 & \\
\hline Women & 9 & 13 & 11 & \\
\hline \multicolumn{5}{|l|}{ Frequency of brushing } \\
\hline$\geq 3$ times/day & 17 & 20 & 16 & \multirow[t]{2}{*}{0.712} \\
\hline 1-2times/day & 6 & 5 & 5 & \\
\hline \multicolumn{4}{|l|}{ Smoking (cigarretes/day) } & \multirow[t]{5}{*}{0.601} \\
\hline No & 14 & 15 & 13 & \\
\hline$<10$ & 7 & 5 & 5 & \\
\hline $10-20$ & 1 & 0 & 0 & \\
\hline$>\mathbf{2 0}$ & 0 & 1 & 0 & \\
\hline \multicolumn{4}{|l|}{ Tooth } & \multirow[t]{3}{*}{0.984} \\
\hline 38 & 11 & 10 & 9 & \\
\hline 48 & 11 & 11 & 9 & \\
\hline \multicolumn{4}{|l|}{ Surgical difficulty } & \multirow[t]{4}{*}{0.587} \\
\hline Easy & 8 & 9 & 7 & \\
\hline Moderate & 12 & 12 & 10 & \\
\hline Difficult & 2 & 0 & 1 & \\
\hline
\end{tabular}

The higher score to the level of compliance was found to the phone call follow-up instructions group $(9.7 \pm 0.5)$ in comparison to brief written instructions (8.5 \pm 1.2$)$ and written extended instructions (7.9 \pm 2.1$)$ groups, being this difference statistically significant (ANOVA $p=0.001$ ) (Table 3).

Regarding the variables most related to non-compliance, in the phone call follow-up instructions group all variables assessed were fulfilled; while in the brief written and extended written instructions groups, hygiene and smoking were the variables that were less fulfilled, being this differences statistically significant $(p<0.001$ and $p=0.026$, respectively), and tended towards significance for NSAID $(p=0.078)$, chlorhexidine rinses $(p=0.075)$ and ATB $(p=0.052)$; the written extended instructions group showed worse results than brief written instructions group (Table 4). dine rinses $14.2 \%(p=0.02)$, NSAID $13.3 \%(p=0.01)$ and carbonated drinks $13.2 \%(p=0.03)$.

\section{Discussion}

A growing number of patients have difficulty to understand and implement postoperative instructions. Applying correctly the postoperative instructions after surgery reduce morbidity, help a fast recovery and improve the quality of life of patients. Schouten et al. (14) found that patients' satisfaction was mainly influenced by the communicative behaviour of the dentist. Anxiety or stress that arises from a surgical procedure may detract the patient's ability to concentrate on information surgeon is given after the surgical procedure $(3,15)$. Alexander et al. (3) found that available written post-surgical procedures instructions in dentistry are replete with poor phrasing; excessive jargon and bad terminology, which may 
Table 4: Relationship between compliance of each assessed variable and study groups.

\begin{tabular}{|c|c|c|c|c|}
\hline Variable & $\begin{array}{l}\text { Brief written } \\
\quad(n=23)\end{array}$ & $\begin{array}{c}\text { Extended } \\
\text { written } \\
(n=25)\end{array}$ & $\begin{array}{l}\text { Phone call } \\
\text { follow-up } \\
(n=21)\end{array}$ & $P$ value \\
\hline \multicolumn{5}{|l|}{ Gauze for 30 minutes } \\
\hline Yes & 22 & 20 & 18 & \multirow[t]{2}{*}{0.339} \\
\hline No & 0 & 1 & 0 & \\
\hline \multicolumn{5}{|l|}{$\begin{array}{l}\text { Mouthwash } \\
\text { (24h after surgery) }\end{array}$} \\
\hline Yes & 21 & 21 & 18 & \multirow[t]{2}{*}{0.355} \\
\hline No & 1 & 0 & 0 & \\
\hline \multicolumn{5}{|l|}{ Soft diet } \\
\hline Yes & 22 & 19 & 18 & \multirow[t]{2}{*}{0.111} \\
\hline No & 0 & 2 & 0 & \\
\hline \multicolumn{5}{|l|}{ Ice (first 24 hours) } \\
\hline Yes & 22 & 18 & 17 & \multirow[t]{2}{*}{0.101} \\
\hline No & 0 & 3 & 1 & \\
\hline \multicolumn{5}{|l|}{ Hygiene } \\
\hline Yes & 7 & 9 & 18 & \multirow[t]{2}{*}{0.0001} \\
\hline No & 15 & 12 & 0 & \\
\hline \multicolumn{5}{|l|}{ Smoking } \\
\hline Yes & 19 & 13 & 17 & \multirow[t]{2}{*}{0.026} \\
\hline No & 3 & 8 & 1 & \\
\hline \multicolumn{5}{|l|}{ Carbonated drinks } \\
\hline Yes & 19 & 15 & 17 & \multirow[t]{2}{*}{0.132} \\
\hline No & 3 & 6 & 1 & \\
\hline \multicolumn{4}{|l|}{ Antibiotics (ATB) } & \multirow[t]{3}{*}{0.052} \\
\hline Yes & 21 & 17 & 18 & \\
\hline No & 1 & 4 & 0 & \\
\hline $\begin{array}{l}\text { Analgesics and anti-inflam- } \\
\text { matories (NSAID) }\end{array}$ & & & & \multirow[t]{3}{*}{0.078} \\
\hline Yes & 15 & 18 & 17 & \\
\hline No & 7 & 3 & 1 & \\
\hline Chlorhexidine rinses & & & & \multirow[t]{3}{*}{0.075} \\
\hline Yes & 18 & 14 & 17 & \\
\hline No & 4 & 7 & 1 & \\
\hline Score & $8.5 \pm 1.2$ & $7.9 \pm 2.1$ & $9.7 \pm 0.5$ & \multirow[t]{2}{*}{0.001} \\
\hline IC $95 \%$ & $7.9-9$ & $7-8.8$ & $9.5-9.9$ & \\
\hline
\end{tabular}

interfere to the compliance of postoperative recommendations. Layton et al. (16) showed that nearly half of patients undergoing third molar surgery failed to recall or recognize at least one of the preoperative verbal instructions given by the doctor. In addition, Vallerand et al. (5) demonstrated that postoperative pain control and satisfaction after third molar surgical extractions were greater in patients who received detailed recommendations and information. The way the information is delivered to patients plays a paramount role in the level of compliance of postoperative recommendations. Alexander et al. (3) showed that without written reinforcement the understanding and retention of verbal instructions over a lengthy period of recovery cannot be assured. Similar results were reported in the study by Atchison et al. (7) who showed that a combination of verbal and written 
instructions are preferred by most patients, particularly those with lower education. Alvira-Gonzalez \& Gay-Escoda (2) did not find statistically significant differences regarding adherence of postoperative care instructions depending on the manner of instruction presentation (verbal, written, additional written instructions), preoperative anxiety level and sociocultural level. Telephone contact with patients has been demonstrated to be a useful tool in providing a means for questions and concerns to be addressed in the critical time for patients and families after surgery (9). A Cochrane review of postoperative phone call follow-ups conducted by various health care professionals for patients discharged from the hospital found that postoperative phone calls made by hospital-based health professionals was considered a good means of information exchange for symptom management, patient instruction and education and early recognition of potential complications (17). In the present study, all patients received verbal instructions; results showed that a reinforcement phone call follow-up at 3-day after surgery showed the best score in compliance of postoperative recommendations statistically significant. Moreover, no differences were found between the group that received brief written instructions and the group that received extended written instructions as Alvira-Gonzalez \& Gay-Escoda (2) found. Hygiene and smoking were the variables more related to the non-compliance with the postoperative recommendation, followed by not performing chlorhexidine rinses and NSAID and ATB prescription. Conrad et al. (18) found that food collection in the surgical sites posed the biggest problem for patients $(20 \%)$. In the present study, a $25.2 \%$ of patients failed in maintaining a proper hygiene during the postoperative period. This might be due to some patients might experience pain and discomfort during brushing of surgical sites as well as ignorance or fear about how clean these areas. So the clinician should educate patients on oral hygiene instructions in order to gain confidence at the time of maintaining hygiene properly. Regarding smoking, over $19 \%$ of smokers continued smoking during the postoperative period. Sweet (19) and Meechan et al. (20) reported that the majority of patients who smoked continued also doing postoperatively. The use of chlorhexidine rinses, NSAID and consumption of carbonated drinks was failed by over $13 \%$ of patients. The main cause of abandonment was relief of pain considering they were able to return to their daily lives without caring on that.

Few data is available regarding the surgeon's explanations and patient comprehension and compliance of postoperative instructions after the surgical extraction of third molars. Future studies are needed to support the results of this RCT to improve the level of communication between the surgeon and the patient.

Telephone call follow-up can promote patient adherence to postoperative recommendations after third molar surgery. The main factors of non-compliance were not maintain a proper hygiene and not smoking, followed by not performing chlorhexidine rinses and not following medication prescribed.

\section{References}

1. Worrall SF, Riden K, Haskell R, Corrigan AM. UK National Third Molar project: The initial report. Br J Oral Maxillofac Surg. 1998;36:14-8

2. Alvira-González J, Gay-Escoda C. Compliance of postoperative instructions following the surgical extraction of impacted lower third molars: A randomized clinical trial. Med Oral Patol Oral Cir Bucal. 2015;20:e224-30.

3. Alexander RE. Patient understanding of postsurgical instruction forms. Oral Surg Oral Med Oral Pathol Oral Radiol Endod. 1999;87:153-8. 4. Blinder D, Rotenberg L, Peleg M, Taicher S. Patient compliance to instructions after oral surgical procedures.Int J Oral Maxillofac Surg. 2001;30:216-19

5. Vallerand WP, Vallerand AH, Heft M. The effects of postoperative preparatory information on the clinical course following third molar extraction. J Oral Maxillofac Surg. 1994;52:1165-70.

6. Kessels RP. Patients' memory for medical information. J R Soc Med. 2003;96:219-22.

7. Atchison KA, Black EE, Leathers R, Belin TR, Abrego M, Gironda $\mathrm{MW}$, et al. A qualitative report of patient problems and postoperative instructions. J Oral Maxillofac Surg. 2005;63:449-56.

8. Hafiji J, Salmon P, Hussain W. Patient satisfaction with post-operative telephone calls after Mohs micrographic surgery: a New Zealand and U.K. experience. Br J Dermatol. 2012;167:570-4.

9. Kassmann BP, Docherty SL, Rice HE, Bailey DC Jr, Schweitzer M. Telephone follow-up for pediatric ambulatory surgery: parent and provider satisfaction. J Pediatr Nurs. 2012;27:715-24.

10. Braun E, Baidusi A, Alroy G, Azzam ZS. Telephone follow-up improves patients satisfaction following hospital discharge. Eur J Intern Med. 2009;20:221-5.

11. McVay MR, Kelley KR, Mathews DL, Jackson RJ, Kokoska ER, Smith SD. Postoperative follow-up: is a phone call enough? J Pediatr Surg. 2008;43:83-6.

12. Fischer K, Hogan V, Jager A, von Allmen D. Efficacy and Utility of Phone Call Follow-up after Pediatric General Surgery versus Traditional Clinic Follow-up. The Permanente Journal. 2015;19:11-14.

13. Moher D, Hopewell S, Schulz K, Montori V, Gotzsche P, Devereaux P, et al. CONSORT 2010 Explanation and Elaboration: Up-dated guidelines for reporting parallel group randomised trials. J Clin Epidemiol. 2010;63:1-37.

14. Schouten BC, Eijkman MA, Hoogstraten J. Dentists' and patients' communicative behaviour and their satisfaction with the dental encounter. Community Dent Health. 2003;20:11-5.

15. Leathers R, Belin TR, Abrego M. A Qualitative Report of Patient Problems and Postoperative Instructions. J Oral Maxillofac Surg. 2005;63:449-56.

16. Layton SA. Informed consent in oral and maxillofacial surgery: a study of its effectiveness. Br J Oral Maxillofac Surg. 1992;30:319-22. 17. Mistiaen P, Poot E. Telephone follow-up, initiated by a hospital-based health professional, for postdischarge problems in patients discharged from hospital to home. Cochrane Database Syst Rev. 2006;4:CD004510.

18. Conrad SM, Blakey GH, Shugars DA, Marciani RD, Phillips C, White RP Jr. Patients' perception of recovery after third molar surgery. J Oral Maxillofac Surg. 1999;57:1288-94; discussion 1295-6.

19. Sweet JB. The relationship of smoking to localized osteitis. J Oral Surg. 1979;37:732-5.

20. Meechan JG, Macgregor DM, Rogers SN, Hobson RS, Bate JPC, Dennison M. The effect of smoking on immediate post-extrac- tion socket filling with blood and on the incidence of painful socket. Br J Oral Maxillofac Surg. 1988;26:402-9.

\section{Conflict of Interest}

Non declared. 